\title{
Desafios na formação do Cirurgião-Dentista para o SUS
}

\author{
Isis Maryana Poczapski Grande*, Rayane Prochnow*, Rafaela Saab*, Eduardo Pizzatto** \\ * Mestranda em Odontologia Clínica, Universidade Positivo \\ ** Docente do Programa de Pós-Graduação em Odontologia Clínica, Universidade \\ Positivo
}

\begin{abstract}
RESUMO
A mudança na estrutura curricular realizada pelas escolas de Odontologia, com a inserção de estágios e clínicas integradas, fez com que o desafio da formação profissional para o Sistema Único de Saúde (SUS) fosse possível. Entretanto, ainda existem cursos e docentes que valorizam a Odontologia tecnicista, distanciando os futuros profissionais do atendimento generalista, que é uma das necessidades do SUS. Estas mudanças curriculares possibilitaram um processo de aprendizagem privilegiado, com a promoção e disseminação de saúde por meio de atividades coletivas, acolhimento ampliado em clínica e participação da sociedade em um trabalho de equipe. Neste contexto, a modificação curricular nos cursos de graduação em Odontologia é de extrema necessidade, porém sabe-se que essa mudança deve ser feita de maneira gradativa e constante, garantindo que as mudanças implementadas sejam eficazes e preparem os acadêmicos à sua vida profissional.
\end{abstract}

Descritores: Educação em Odontologia. Sistema Único de Saúde. Saúde da Família. 


\section{INTRODUÇÃO}

Atualmente, no Brasil, nota-se a necessidade da renovação curricular do ensino em saúde, para que os futuros profissionais sejam capacitados ao atendimento no Sistema Único de Saúde (SUS). Neste sentido, medidas vêm sendo tomadas a fim de incluir, durante a graduação, o contato do acadêmico com o ambiente de Saúde Pública. ${ }^{1}$

O ensino da Odontologia segue, ainda, um padrão de formação profissional marcado pela necessidade de especialização e aprofundamento em temas complexos, limitando assim a formação generalista do cirurgião-dentista para atendimento em saúde pública. A necessidade de abrangência nas diversas áreas da Odontologia é crucial para que o profissional perceba o paciente em todas as suas necessidades. Portanto, para superar o desafio da educação para o SUS, são propostas reorganizações das Diretrizes Curriculares Nacionais (DCN) para os cursos de graduação em Odontologia. ${ }^{2}$

Uma das propostas para integração do graduando ao atendimento clínico é através de estágios supervisionados, visto ainda como uma das maiores inovações para diversas escolas. $\mathrm{O}$ estágio não deve caracterizar práticas antigas, já realizadas com velhos protocolos, e sim propor alternativas que proporcionem ao acadêmico o contato direto com a realidade encontrada nos serviços públicos de saúde, entendendo seus limites e possibilidades de atendimento. ${ }^{3}$

Profissionais capazes de prevenir, tratar e promover saúde são de extrema importância, porém ainda são formados cirurgiões-dentistas tecnicistas, que praticam uma Odontologia tradicional, individualista, autônoma e curativa, sem avaliar a real necessidade de condicionamento do paciente por meio da avaliação do contexto macrossocial no qual ele está inserido. ${ }^{4}$

O objetivo deste artigo é discutir, por meio de uma revisão de literatura, o processo de formação do cirurgião-dentista para o atendimento no SUS.

\section{METODOLOGIA}

Para o estudo foi utilizada a seguinte estratégia de seleção de artigos: realizou-se busca nas bases eletrônica de dados BBO, ISI, LILACS, MEDLINE e SciELO, utilizando-se os descritores em ciências da saúde "Educação em Odontologia", "Sistema Único de Saúde" e "Saúde da Família". Foram selecionados os artigos publicados na íntegra em português, inglês ou espanhol, entre 2003 e 2015 . Os títulos e resumos foram lidos para a seleção final.

\section{RESULTADOS E DISCUSSÃO}

A prática clínica do cirurgião-dentista ainda é reflexo de uma odontologia baseada no modelo Flexneriano, com prática curativa, tecnicista, especializada, biologicista e individualista, com pouco enfoque na prevenção e promoção de saúde. Apesar da incorporação dos princípios (equidade, integralidade, regionalização e hierarquização) e diretrizes do SUS nos municípios brasileiros, os profissionais inseridos na saúde pública não trazem um conhecimento capaz de cumprí-las. ${ }^{4}$

Uma das propostas das DCN para vencer o desafio da educação integral para o SUS se dá por meio da inclusão de estágios no serviço público, desde os períodos iniciais da graduação, promovendo uma visão multidisciplinar e integração com diversas áreas da saúde..$^{5}$

Um estudo realizado na universidade de Londrina avaliou a efetividade da implementação de clínicas integradas, onde o aluno atua na saúde bucal de forma completa, adquirindo assim excelência técnica e estando apto a atuar em diversas áreas da Odontologia, apresentando maior senso crítico a fim de alcançar um diagnóstico ampliado da situação. ${ }^{6}$

Políticas de inclusão social que vêm sendo implementadas pelo Governo Federal e têm mostrado resultados expressivos nas áreas sociais. Constantes esforços vêm sendo realizados há algum tempo na área de saúde, para que algumas mudanças sejam feitas no modelo tradicional de organização do cuidado. O Ministério da Saúde, por meio da Secretaria de Gestão do Trabalho e da Educação na Saúde (SGTES) em parceria com a Secretaria de Educação Superior (SESU) e com o 
Instituto Nacional de Estudos e Pesquisas Educacionais Anísio Teixeira (INEP), do Ministério da Educação (MEC), e com o apoio da Organização Pan-Americana da Saúde (OPAS), implementaram o Programa Nacional de Reorientação da Formação Profissional em Saúde (Pró-Saúde). Esse programa traz uma nova visão dos serviços de saúde, reorientando os profissionais, orientando que os tratamentos devem seguir três eixos principais: (a) clareza na abordagem conceitual; (b) orientação quanto à regulação e sistema de referência; e (c) integração do hospital de ensino nas redes de serviço, e indicação de parâmetros de avaliação. ${ }^{7}$

A introdução do programa Pró-Saúde tem mostrado mudanças positivas nos cursos de Odontologia, pois com a modificação da carga horária e inclusão de ações voltadas ao SUS, os alunos têm mais acesso à realidade deste sistema. ${ }^{8}$

Delinear uma carga horária mínima de dedicação do aluno à atenção primária à saúde durante a sua formação é uma experiência já realizada por algumas instituições de ensino, e se mostrou efetiva para o entendimento de que problemas básicos de saúde bucal são predominantes. Sendo assim, as instituições inserem seus alunos nessas áreas, disponibilizando tempo necessário para o aprendizado em serviço. ${ }^{9}$

A inserção dos alunos no serviço de saúde é bem vista por aqueles que atuam neste meio e vêem a importância da inclusão destes logo no início do curso, para que possam ter uma visão geral das limitações do SUS, tornando-os futuros profissionais capacitados ao atendimento público. ${ }^{3}$

Diante da saturação do mercado de trabalho os cursos vêm buscando formar não apenas meros profissionais, mas sim indivíduos que saibam atuar tanto de forma autônoma quanto de forma pública, estimulando o senso de cidadania. Com isso, o profissional passa a se interessar mais pela comunidade na qual está inserido. ${ }^{10}$

Ainda há uma barreira nas estruturas curriculares em relação ao processo de integração das especialidades odontológicas e de formação generalista, apesar de ser um remanejamento curricular longo e demorado, seus resultados serão vantajosos tanto aos pacientes que utilizam o SUS quanto aos profissionais envolvidos. ${ }^{11}$

O alargamento da visão dos novos profissionais da Odontologia é um dos pontos positivos da inserção de estágios na estrutura curricular. Segundo um estudo qualitativo, os acadêmicos que participaram do projeto de extensão "Nós na rede", dedicado ao acolhimento das demandas educativas, preventivas e curativas em saúde bucal do público da comunidade da região, da Universidade Estadual de Ponta Grossa, ampliam as suas concepções dos processos saúdedoença e da realidade da comunidade, preparandose para o SUS. ${ }^{12}$

Os estágios supervisionados no SUS oferecem um processo de aprendizagem privilegiado, não só sobre a produção de saúde, mas também no cuidado, promovendo atividades coletivas, acolhimento ampliado em clínica e a participação da sociedade, em um trabalho de equipe. $^{13}$

Estudo realizado em uma universidade do Espírito Santo com foco no programa PET-Saúde mostrou impacto positivo na formação dos acadêmicos, que tiveram uma melhora na autoconfiança relacionada à pratica profissional, que só pode ser obtida por meio da vivência em unidades de saúde da família. Além disso, conseguiu-se formação mais humanista e integral. ${ }^{14}$

Os estágios extramuros, quando realizados dentro nas unidades de saúde, trazem aos graduandos uma vivência prática sobre a realidade social da comunidade, além de incentivar o trabalho em equipe e com isso otimizar o atendimento humanista. ${ }^{1}$

Em tempos de mudança no currículo dos cursos de Odontologia, não é suficiente que as disciplinas se adaptem à atenção primária, pois um trabalho deste nível de mudança requer $o$ envolvimento de vários atores, tais como universidade, alunos e todo o corpo docente. ${ }^{9}$

A realidade prática dentro do SUS vem sofrendo alterações, com isso os alunos envolvidos 
neste meio, aos poucos vêm melhorando o conceito denegrido pela mídia em torno do sistema, que ainda necessita grandes mudanças. ${ }^{8}$

O conhecimento por parte dos profissionais é primordial em relação ao programa Pró-Saúde, pois este vem desempenhando um importante papel social na saúde bucal da população brasileira. ${ }^{8}$ Algumas dificuldades encontradas na inserção dos alunos de Odontologia no SUS se devem, em grande parte, ao desinteresse dos graduandos frente aos problemas da comunidade, devido à falta de estimulo a saberes pedagógicos e governamentais, onde os docentes privilegiam, em sua maioria, os saberes técnicos. ${ }^{2}$

Apesar da necessidade de uma formação generalista voltada para a atenção primária, vale salientar que especialidade ainda é necessária, e o SUS mantêm o padrão de encaminhamento para casos complexos, quando a abordagem de um especialista se faz necessária. ${ }^{15}$

\section{CONCLUSÃO}

A modificação na estrutura curricular nos cursos de Odontologia é de extrema necessidade, porém sabe-se que essa mudança deve ser feita de maneira gradativa e constante, garantindo que as mudanças implementadas sejam de fato eficazes para preparar os acadêmicos a sua vida profissional, sendo ela dentro ou fora do Sistema Único de Saúde.

\section{ABSTRACT}

Challenges in the formation of Dentist to the SUS The curricular changes carried out by Dental Schools, with the inclusion of internships and integrated clinical work, made the challenge of training for the Unified Health System (SUS) possible. However, there are still courses and teachers that value the technical Dentistry, distancing the future professionals of the general practice, which is one of the SUS needs. These curricular changes allowed a privileged learning process, with the promotion and dissemination of health through collective activities in clinical care and expanded participation of society in a team effort. In this context, curricular modification in undergraduate courses in dentistry is extremely need, but it is known that should be made gradually and steadily, ensuring that the changes implemented are effective and prepare the students for their professional life.

Descriptors: Dental Education. Unified Health System. Family Health.

\section{REFERÊNCIAS}

1. Leme PAT, Pereira AC, Meneghim MC, Mialhe FL. Undergraduate dental students' perspectives about experiences in primary care for their education in the Field of health. Ciên Saúde Colet 2015;20(4):1255-65.

2. Guimarães FAF, Mello ALSF, Pires ROM. Formação profissional em odontologia: Revisão de Literatura. Rev Saúde Públ Santa Cat 2014; 7(3):75-87.

3. Palmier AC, Amaral JHL, Werneck MAF, Senna MIB, Lucas SD. Inserção do aluno de Odontologia no SUS: Contribuições do PróSaúde. Rev Bras Educ Méd 2012; 36(1, Supl.2): 152-57.

4. Pereira DQ, Pereira JCM, Assis MMA. The odontological practice in the Basic Health Units in Feira de Santana, Bahia, in the health municipalization process: individual, autonomous, curative and technical activities. Ciên Saúde Colet 2003;8(2):599-609.

5. Werneck MAF, Senna MIB, Drumond MM, Lucas SD. Not everything is supervised training: contributions for the debate. Ciên Saúde Colet 2010; 15(1):221-231.

6. Gabriel M, Tanaka EE. Formação profissional em Odontologia: Percepção discente da interação curricular. Rev ABENO 2011;11(1):19-22.

7. Brasil. Ministério da Saúde. Ministério da Educação. Programa Nacional de Reorientação da Formação Profissional em Saúde - PRÓ-SAÚDE - Objetivos, implementação e desafios profissionais. Brasília/DF. 2007.

8. Rodrigues CRC, Silva MAM. O impacto dos 
cenários de pratica propostos pelo pró-saúde na formação em odontologia. Rev ABENO 2012;12(2):219-26.

9. Silva MAM, Amaral JHL, Senna MIB, Ferreira EF. O Pró-Saúde e o incentivo à inclusão de espaços diferenciados de aprendizagem nos cursos de odontologia do Brasil. Interface 2012;16(42):707-17.

10. Saliba NA, Moimaz SAS, Prado RL, Garbin CAS. Perception of dentists about professional training and difficulties of insertion in the labor market. Rev Odontol UNESP 2012;41(5):297-304.

11. Toassi RFC, Souza JM, Baumgarten A, Rõsing CK. Avaliação curricular na educação superior em odontologia: discutindo as mudanças curriculares na formação em saúde no Brasil. Rev ABENO 2012;12(2):170-7.

12. Fadel CB, Bordin D, Kuhn E, Martins LD. O impacto da extensão universitária sobre a formação acadêmica em Odontologia. Interface 2013; 17(47):937-42.
13. Baumgarten A, Toassi RFC. The formation of dentists in Unified Health System: the production of health care. Rev Bras Pesq Saúde 2013;15(4):117-122.

14. Santos KT, Ferreira L, Batista RJ, Bitencourt CTF, Araújo RP, Carvalho RB. Rev Odontol UNESP 2013;42(6):420-425.

15. Xavier GM. A formação do cirurgião-dentista no contexto do sistema único de saúde: Uma avaliação do ensino de Odontologia. (Dissertação). Brasília (DF): Universidade de Brasília; 2013

Correspondência para:

Isis Maryana Poczapski Grande

e-mail: isismaryana@hotmail.com

Universidade Positivo

Rua Prof. Pedro Viriato Parigot de Souza, 5300

Cidade Industrial

81280-330 Curitiba, PR 